引用格式: 戴桂林, 林春宇, 付秀梅, 等. 中国海洋药用生物资源可持续利用潜力评价一一基于熵权-层次分析法 [J]. 资源科学, 2017, 39 (11):2176-2185. [Dai G L, Lin C Y, Fu X M, et al. Evaluation on the sustainable utilization potential of marine medicinal bioresources in China based on Entropy-AHP[J]. Resources Science, 2017,39(11):2176-2185.] DOI: 10.18402/resci.2017.11.15

\title{
中国海洋药用生物资源可持续利用潜力评价 基于摘权-层次分析法
}

\author{
戴桂林 ${ }^{1}$, 林春宇 ${ }^{1}$, 付秀梅 ${ }^{1}$, 王 娜 ${ }^{1}$, 李于森 ${ }^{1}$
}

(中国海洋大学经济学院, 青岛 266100)

\begin{abstract}
摘＼cjkstart要: 本文对中国沿海 11 省市 (不包括港澳台)海洋药用生物资源的利用潜力进行了定量测算以及等级划 分, 并对各省海洋生物医药产业的发展潜力做出了比较评价, 为相关省区海洋药用生物资源优化配置及其产业合 理布局提供决策参考。论文从自然条件、经济与技术条件和社会条件三个层面, 选取 20 个影响海洋药用生物资源 潜力的因素, 运用摘权法和层次分析法, 确定了 20 个影响因子在海洋药用生物资源潜力评价中的权重值, 建立海洋 药用生物资源可持续利用潜力的评价体系。评价指标中的政策支持强度、海洋药品市场辐射能力、环境多样性、药 用资源供给数量以及药用资源研发水平的权重居于前五位, 表明该 5 项指标是影响海洋药用生物资源开发利用潜 力的主要因素。通过实证分析,将中国大陆沿海 11 个省市的海洋药用生物资源可持续利用潜力进行排序和分级, 结果依次为: 第 1 级有广东、浙江; 第 2 级有海南、山东、福建、江苏、广西、上海; 第 3 级有天津、辽宁、河北。结合主要 影响指标贡献度, 从国家总体和各省分级层面提出了对策与建议, 以期有利于提高海洋药用生物资源的可持续利 用潜力。
\end{abstract}

关键词: 海洋药用生物资源; 可持续利用;潜力评价; 摘权法;层次分析法

DOI: $10.18402 /$ resci.2017.11.15

\section{1 引言}

随着环境污染的加剧和人类疾病谱的改变, 人 类迫切需要开辟新药途径。特殊的海洋生态环境 赋予着海洋生物特殊的药效。孕育而生的海洋生 物医药产业已经成为各个海洋国家战略性新兴产 业发展的重点。中国是海洋大国，根据《20132017 年中国海洋生物医药产业深度调研与投资战 略规划分析报告》“数据显示, 在 2011-2020年中国 海洋生物医药产业在未来的发展将步人一个全面 向好的时期,最终将成为促进中国海洋经济增长的 新引擎。因此, 探明海洋药用生物资源开发利用潜 力状况, 对于中国海洋医药产业的合理布局、发展 中国海洋生物医药产业以及结构升级转型均具有
现实意义。

海洋生物药物指的是以海洋生物为原料,运用 现代方法和技术得到的有效药物, 包括海洋植物 药、海洋动物药和海洋微生物药。海洋药用生物资 源可持续发展潜力是海洋生物医药产业的基础, 对 海洋生物医药产业发展具有重要意义 ${ }^{[2]}$ 。

中国目前在社会、经济与环境等领域建立了多 种评价指标体系,其中在资源环境领域包括对水资 源、生态环境质量与建设、退化生态系统、湿地生 态、土地资源以及资源条件等进行了评价 ${ }^{[3]}$ 。中国 对药用生物资源评价研究主要集中在陆地药物资 源评价,包括实地调查的方法 ${ }^{[4,5]}$ 评价陆地药用生物 资源; 运用层次分析法、德尔菲(Delphi)调查法 ${ }^{[6,7]}$ 对

收稿日期: 2017-02-10; 修订日期: 2017-09-18

基金项目: 教育部新世纪优秀人才支持计划(NCET-07-0777); 国家海洋局软科学项目(G.2200205.150301); 广西科技兴海专项 (GXZC2014-G3-0578-KLZB(C))。

作者简介: 戴桂林, 男, 山东烟台人, 教授, 博士生导师, 主要研究方向为海洋经济、资源开发战略与评价。E-mail: oucdaiguilin@qq.com 通讯作者:付秀梅,E-mail : fuxiumei92@163.com 
子系统 $\left(B_{3}\right)$ 三个方面的评价。每个子系统再分设若

具体陆地某一区域的药用资源进行评价,评价指标 权重大多用主观赋权法分析。针对海洋药用生物 资源研究, 目前中国学者多是以实地调查考察、民 间调查访问、海洋药用生物历史文献和数据资料收 集的方式来进行调查 ${ }^{[7-9]}$, 主要侧重于资源物种分 类、分布和药理与药效方面的定性评价; 同时也有 针对海洋药用生物资源开发利用状况进行保护方 面的论述 ${ }^{[10]}$ 。到目前为止, 尚未见到关于海洋药用 生物资源系统整体的评价, 缺少对海洋药用生物资 源可持续利用发展潜力定性与定量的评价探讨。

本文基于海洋药用生物资源系统是一个“生态经济-社会”复合系统和各要素关系复杂等特点,运 用层次分析法、熵权法、主观和客观评价方法相结 合, 从生态、经济和社会三个层次构建海洋药用生 物资源可持续利用潜力评价指标体系,通过层次分 析法和熵权法确定权重,据此对中国沿海 11 个省市 (不包括台湾、香港和澳门)海洋药用生物资源可持 续利用潜力进行评价, 以期为中国沿海 11 个省市海 洋药用生物资源可持续利用、统筹海洋生物医药产 业布局与发展, 提供决策参考。

\section{2 研究方法与数据来源}

\section{1 研究思路与路径}

从自然条件、经济与技术条件以及社会条件三 个层面人手,辨析影响中国海洋药用生物资源开发 利用的主要因素,选取 20 个影响海洋药用生物资源 潜力评价的核心指标,构建海洋药用生物资源利用 潜力评价体系。通过面询与问卷相结合的方式对 20 个指标的重要性进行专家打分, 再运用层次分析 法和熵权法相结合的方法确定 20 个指标的权重值, 对指标进行排序和分析。最后,通过实证分析, 客 观评价中国沿海 11 个省市的海洋药用生物资源 潜力。

\section{2 评价指标体系构建}

人类社会是以人的行为为主导、自然环境为依 托、资源流动为命脉、社会文化为经络的“社会-经 济-自然”复合生态系统。只有这三个子系统耦合关 系和谐有序,才能实现人类社会、经济与环境之间 复合生态关系的可持续发展 ${ }^{\left[{ }^{[12]}\right.}$ 。因此,本研究评价 海洋药用生物资源可持续利用潜力指标体系,包括 对自然子系统 $\left(B_{1}\right)$ 、技术与经济子系统 $\left(B_{2}\right)$ 和社会 干个指标。

(1) 自然子系统 $\left(B_{1}\right)$ 设 3 个相关评价指标, 分别 是当地资源丰度 $\left(C_{1}\right)$ 、资源再生能力 $\left(C_{2}\right)$ 以及资源 供给能力 $\left(C_{3}\right)$ 。

(2) 技术与经济子系统 $\left(B_{2}\right)$ 。海洋药用生物资 源是人类运用技术开发利用、发展经济的物质基 础。海洋药用生物资源理论储藏量很大,但是因受 开发利用技术条件等的约束,其可收集或者可利用 的资源量不一定很大。海洋技术与经济子系统是 相互作用、相互依赖的各海洋产业组成的具有特定 功能的有机整体 ${ }^{[13]}$, 海洋药用生物资源开发利用方 案是否可行与其具体技术成熟度和经济可行性密 切相关,而且市场需求对海洋药用生物技术发展也 有一定的影响。此外, 因为海洋药用生物种类繁 多,各类海洋药用生物技术又处于不同发展阶段， 本文用整体技术水平进行代表。因此在技术与经 济子系统 $\left(B_{2}\right)$ 中设 2 个相关评价指标, 分别为技术 成熟度 $\left(C_{4}\right)$ 和市场需求程度 $\left(C_{5}\right)$ 。

(3) 社会子系统 $\left(B_{3}\right)$ 。海洋药用生物资源开发 利用与社会各利益相关者密切相关, 利益相关者包 括政府、公众等;各利益者的支持和关注程度影响 海洋药用生物资源开发利用。因此在社会子系统 $\left(B_{3}\right)$ 中设 4 个相关评价指标, 分别为政策支持强度 $\left(C_{6}\right)$ 、公众支持程度 $\left(C_{7}\right)$ 、创造就业机会 $\left(C_{8}\right)$ 以及收 人增长 $\left(C_{9}\right)$ 。

根据每个要素层自身特点,进一步划分为不同 的指标; 按照层次不同,每个要素层包含不同的指 标层, 总共选取 20 个指标, 见表 1 。

\section{3 指标权重确定及分析}

权重的确定在综合评价中占有非常重要的位 置, 其大小对评估结果十分重要。本研究通过 AHP 构建评价体系, 利用并结合 Delphi 调查法(德尔菲 法）、熵值法,计算各指标的权重。采用面询和函询 相结合的方式由相关专家对该评价系统中各项评 价指标进行评价, 最后将评价结果录人各项指标, 并计算各指标权重和判断矩阵一致性比例。各指 标的权重及判断矩阵一致性,约束层权重 $\left(W B_{i}\right)$ 、标 准层权重 $\left(W C_{i}\right)$ 、综合评价指标权重 $\left(W_{i}\right)$ 间关系是 $W_{i}=W B_{i} \times W C_{i}$ 。制约层和要素层判断矩阵一致性 
表 1 中国海洋药用生物资源潜力评价指标体系

Table 1 China marine medicinal bioresources potential evaluation index

\begin{tabular}{llll}
\hline 目标层 & 制约层 & 要素层 & 指标层 \\
\hline 中国海洋药用生物资源潜力评价 & 自然条件 $B_{1}$ & 资源丰度 $C_{1}$ & 环境多样性 $D_{1}$ \\
& & 可药用资源种类 $D_{2}$ \\
& & 可药用资源总量 $D_{3}$ \\
& & 人均药用资源量 $D_{4}$ \\
& 资源再生能力 $C_{2}$ & 药用资源占海洋生物比重 $D_{5}$ \\
& & 可养殖药用资源种类 $D_{6}$ \\
& & 可养殖药用资源数量 $D_{7}$ \\
& 资源供给能力 $C_{3}$ & 药用资源供给种类 $D_{8}$ \\
& & 药用资源供给数量 $D_{9}$ \\
& 经济与技术条件 $B_{2}$ & 技术成熟度 $C_{4}$ & 药用资源研发水平 $D_{10}$ \\
& & 海洋药品市场化水平 $D_{11}$ \\
& 市场需求程度 $C_{5}$ & 海洋药品市场知名度 $D_{12}$ \\
& & 海洋药品市场辐射能力 $D_{13}$ \\
& & 海洋药品市场饱和度 $D_{14}$ \\
& & 政策支持强度 $D_{15}$
\end{tabular}

比例分别见表 2、表3。

相关专家依据打分标准对要素层各指标进行 打分, 其实际得分是专家组的加权平均值, 用 $C_{i}$ 表 示。约束层中各子系统的得分 $\left(B_{i}\right), B_{i}=W C_{i} \times C_{i}$, 其中 $W C_{i}$ 为相应子系统中第 $i$ 项指标的权重值; 最 后的综合得分 $(A)$ 用公式表示为 $A=W B_{i} \times B_{i}$, 其中 $W B_{i}$ 为第 $i$ 项子系统的权重值。

由表 $2 、$ 表 3 可得,要素层和制约层的判断矩阵 一致性比例 $C R<0.1$ 均成立, 可得层次单排序和层次

\section{表 2 制约层判断矩阵一致性比例}

Table 2 Consistency proportion of judgment matrix for control layer

\begin{tabular}{lccc}
\hline 制约层 & 自然条件 $B_{1}$ & 经济与技术条件 $B_{2}$ & 社会条件 $B_{3}$ \\
\hline $\begin{array}{l}\text { 判断矩阵 } \\
\text { 一致性比例 }\end{array}$ & 0 & 0 & 0.0846 \\
\hline
\end{tabular}

总排序均满足一致性结果, 层次分析法各项指标权 重均符合要求。

通过专家调查问卷形式,由专家对各项指标重 要性进行打分, 根据沿海 11省实际情况, 对沿海 11 个省的各项指标打分,运用熵权法可得各项指标权 重。本文运用层次分析法获取的主观权重 $w_{i}$ 与运 用熵权法获取的客观权重 $u_{i}$ 进行耦合, 从而获取最 底层各指标相对于最高层的复合权重 $\lambda_{i}$ : $\lambda_{i}=a w_{i}+(1-a) u_{i}$, 其中 $0 \leqslant a \leqslant 1$ 。从公式中可以看 出复合权重随着 $a$ 的变化而发生改变, 当 $a=0$ 和 $a=1$ 的时候,复合权重分别对应于客观权重(熵权 法)和主观权重(层次分析法), 本文确定 $a=0.5$, 可 得海洋药用生物资源可持续发展潜力评价指标权 重值, 见表 4 。

表 3 要素层判断矩阵一致性比例

Table 3 Consistency proportion of judgment matrix for element layer

\begin{tabular}{|c|c|c|c|c|c|c|c|c|c|}
\hline 要素层 & $\begin{array}{c}\text { 资源丰度 } \\
C_{1}\end{array}$ & $\begin{array}{c}\text { 资源再生 } \\
\text { 能力 } C_{2}\end{array}$ & $\begin{array}{c}\text { 资源供给 } \\
\text { 能力 } C_{3}\end{array}$ & $\begin{array}{c}\text { 技术成熟度 } \\
C_{4}\end{array}$ & $\begin{array}{c}\text { 市场需求 } \\
\text { 程度 } C_{5}\end{array}$ & $\begin{array}{c}\text { 政策支持 } \\
\text { 强度 } C_{6}\end{array}$ & $\begin{array}{c}\text { 公众支持 } \\
\text { 强度 } C_{7}\end{array}$ & $\begin{array}{c}\text { 创造就业 } \\
\text { 机会 } C_{8}\end{array}$ & $\begin{array}{c}\text { 收人增长 } \\
C_{9}\end{array}$ \\
\hline $\begin{array}{l}\text { 判断矩阵一 } \\
\text { 致性比例 }\end{array}$ & 0.05 & 0 & 0 & 0 & 0.0213 & 0 & 0 & 0 & 0 \\
\hline
\end{tabular}




\section{表 4 海洋药用生物资源可持续发展潜力评价指标权重值}

Table 4 The evaluation weight of marine medicinal bioresources sustainable development potential

\begin{tabular}{|c|c|c|c|c|c|c|}
\hline 制约层/权重 & 要素层/权重 & 指标层 & $\begin{array}{c}\text { 指标层 } \\
\text { 权重 }\end{array}$ & $\begin{array}{c}\text { 综合评价 } \\
\text { 权重 }\end{array}$ & $\begin{array}{c}\text { 熵权法 } \\
\text { 权重 }\end{array}$ & $\begin{array}{l}\text { 最终 } \\
\text { 权重 }\end{array}$ \\
\hline \multirow[t]{9}{*}{ 自然条件 $B_{1} / 0.3119$} & 资源丰度 $C_{1} / 0.5714$ & 环境多样性 $D_{1}$ & 0.4351 & 0.0775 & 0.0632 & 0.0704 \\
\hline & & 可药用资源种类 $D_{2}$ & 0.3066 & 0.0546 & 0.0440 & 0.0493 \\
\hline & & 可药用资源总量 $D_{3}$ & 0.2231 & 0.0398 & 0.0416 & 0.0407 \\
\hline & & 人均药用资源量 $D_{4}$ & 0.0352 & 0.0063 & 0.0427 & 0.0245 \\
\hline & 资源再生能力 $C_{2} / 0.1429$ & 药用资源占海洋生物比重 $D_{5}$ & 0.0667 & 0.0030 & 0.0428 & 0.0230 \\
\hline & & 可养殖药用资源种类 $D_{6}$ & 0.4667 & 0.0208 & 0.0480 & 0.0344 \\
\hline & & 可养殖药用资源数量 $D_{7}$ & 0.4667 & 0.0208 & 0.0602 & 0.0405 \\
\hline & 资源供给能力 $C_{3} / 0.2857$ & 药用资源供给种类 $D_{8}$ & 0.2500 & 0.0223 & 0.0764 & 0.0493 \\
\hline & & 药用资源供给数量 $D_{9}$ & 0.7500 & 0.0668 & 0.0602 & 0.0635 \\
\hline \multirow[t]{5}{*}{ 经济与技术条件 $B_{2} / 0.1976$} & 技术成熟度 $C_{4} / 0.1429$ & 药用资源研发水平 $D_{10}$ & 0.7500 & 0.0212 & 0.0888 & 0.0550 \\
\hline & & 海洋药品市场化水平 $D_{11}$ & 0.2500 & 0.0071 & 0.0542 & 0.0307 \\
\hline & 市场需求程度 $C_{5} / 0.8571$ & 海洋药品市场知名度 $D_{12}$ & 0.0982 & 0.0166 & 0.0575 & 0.0370 \\
\hline & & 海洋药品市场辐射能力 $D_{13}$ & 0.5679 & 0.0962 & 0.0563 & 0.0763 \\
\hline & & 海洋药品市场饱和度 $D_{14}$ & 0.3339 & 0.0566 & 0.0427 & 0.0497 \\
\hline \multirow[t]{6}{*}{ 社会条件 $B_{3} / 0.4905$} & 政策支持强度 $C_{6} / 0.6463$ & 政策支持强度 $D_{15}$ & 1.0000 & 0.3170 & 0.0435 & 0.1802 \\
\hline & 公众支持强度 $C_{7} / 0.1860$ & 公众了解程度 $D_{16}$ & 0.5000 & 0.0456 & 0.0311 & 0.0383 \\
\hline & & 公众认可程度 $D_{17}$ & 0.5000 & 0.0456 & 0.0427 & 0.0441 \\
\hline & 创造就业机会 $C_{8} / 0.1201$ & 海洋药业增加岗位数量 $D_{18}$ & 0.5000 & 0.0295 & 0.0345 & 0.0320 \\
\hline & & 海洋药业增加岗位水平 $D_{19}$ & 0.5000 & 0.0295 & 0.0349 & 0.0322 \\
\hline & 收入增长 $C_{9} / 0.0476$ & 全国人均收人增长 $D_{20}$ & 1.0000 & 0.0232 & 0.0346 & 0.0289 \\
\hline
\end{tabular}

各指标的层次分析法权重和熵权法权重复合 后,可得最终指标权重,最终指标权重从大到小排 序,见表 5。

(1)制约层指标权重结果评价:

(1)根据表 4 权重计算结果,制约层权重大小排 序为社会条件 $\left(B_{3}\right)>$ 自然条件 $\left(B_{1}\right)>$ 经济与技术条件 $\left(B_{2}\right)$ 。表明海洋药用生物资源潜力评价与社会条件 关系最为密切,即社会条件越好, 对海洋药用生物
资源开发利用促进作用越大,海洋药用生物资源潜 力就越高。自然条件 $\left(B_{1}\right)$ 对海洋药用生物资源潜力 的影响要大于经济与技术条件 $\left(B_{2}\right)$, 因为自然条件 是开发利用海洋药用生物资源物质基础,经济与技 术的发展离不开自然资源, 自然禀赋对经济与技术 的发展具有重要作用。因此,对海洋药用生物资源 潜力评价需要考虑社会条件的有效环境,依据自然 条件情况,结合经济与技术条件进行综合分析。

\section{表 5 最终权重排序}

Table 5 The final weight rank

\begin{tabular}{|c|c|c|c|c|c|c|c|c|c|c|}
\hline 评价指标 & $\begin{array}{c}\text { 政策支持 } \\
\text { 强度 } \\
D_{15}\end{array}$ & $\begin{array}{l}\text { 海洋药品 } \\
\text { 市场辐射 } \\
\text { 能力 } D_{13}\end{array}$ & $\begin{array}{c}\text { 环境 } \\
\text { 多样性 } \\
D_{1}\end{array}$ & $\begin{array}{c}\text { 药用资源 } \\
\text { 供给数量 } \\
D_{9}\end{array}$ & $\begin{array}{c}\text { 药用资源 } \\
\text { 研发水平 } \\
D_{10}\end{array}$ & $\begin{array}{c}\text { 海洋药品 } \\
\text { 市场饱和度 } \\
D_{14}\end{array}$ & $\begin{array}{c}\text { 药用资源 } \\
\text { 供给种类 } \\
D_{8}\end{array}$ & $\begin{array}{c}\text { 可药用 } \\
\text { 资源种类 } \\
D_{2}\end{array}$ & $\begin{array}{c}\text { 公众认可 } \\
\text { 程度 } \\
D_{17}\end{array}$ & $\begin{array}{c}\text { 可药用 } \\
\text { 资源总量 } \\
D_{3}\end{array}$ \\
\hline 最终权重 & 0.1802 & 0.0763 & 0.0704 & 0.0635 & 0.0550 & 0.0497 & 0.0493 & 0.0493 & 0.0441 & 0.0407 \\
\hline 评价指标 & $\begin{array}{c}\text { 可养殖药用 } \\
\text { 资源数量 } \\
D_{7}\end{array}$ & $\begin{array}{c}\text { 公众了 } \\
\text { 解程度 } \\
D_{16}\end{array}$ & $\begin{array}{c}\text { 海洋药品市 } \\
\text { 场知名度 } \\
D_{12}\end{array}$ & $\begin{array}{c}\text { 可养殖药用 } \\
\text { 资源种类 } \\
D_{6}\end{array}$ & $\begin{array}{c}\text { 海洋药业增 } \\
\text { 加岗位水平 } \\
D_{19}\end{array}$ & $\begin{array}{c}\text { 海洋药业增 } \\
\text { 加岗位数量 } \\
D_{18}\end{array}$ & $\begin{array}{c}\text { 海洋药品市 } \\
\text { 场化水平 } \\
D_{11}\end{array}$ & $\begin{array}{c}\text { 全国人均收 } \\
\text { 人增长 } \\
D_{20}\end{array}$ & $\begin{array}{c}\text { 人均药用 } \\
\text { 资源量 } \\
D_{4}\end{array}$ & $\begin{array}{c}\text { 药用资源占 } \\
\text { 海洋生物 } \\
\text { 比重 } D_{5}\end{array}$ \\
\hline 最终权重 & 0.0405 & 0.0383 & 0.0370 & 0.0344 & 0.0322 & 0.0320 & 0.0307 & 0.0289 & 0.0245 & 0.0230 \\
\hline
\end{tabular}


(2)在制约层自然条件子系统中, 要素层权重大 小排序为 $C_{1}>C_{3}>C_{2}$ 。 表明海洋药用生物资源潜力 的自然条件与药用资源丰度关系最为密切。药用 资源越丰富, 资源潜力就越大 ; 反之, 资源丰度越 低,资源潜力就越小。因此资源丰度对海洋药用生 物资源开发有重要影响。

(3)在制约层经济与技术条件子系统中,要素层 权重大小排序为 $C_{5}>C_{4}$ 。表明海洋药用生物资源潜 力的经济与技术条件与市场需求程度的关系最为 密切,其次是技术成熟度。在市场机制作用下,市 场需求程度越高,越能吸引资金、人才的集聚,发挥 集聚作用, 从而提高海洋生物医药技术成熟度, 增 强海洋药用生物资源潜力。

(4)在制约层社会条件子系统中,要素层的权重 大小排序为 $C_{6}>C_{7}>C_{8}>C_{9}$ 。 表明海洋药用生物资源 开发潜力的社会条件与政府支持强度关系密切。 政府支持力度越强, 资源开发潜力就越大。因此, 海洋药用生物资源开发过程中, 首先要充分考虑的 是社会环境条件的问题。

(2)要素层评价指标权重结果评价:

(1)由表 5 可知,评价指标中的政策支持强度、海 洋药品市场辐射能力、环境多样性、药用资源供给 数量以及药用资源研发水平的权重居于前 5 位, 说 明这 5 项指标对海洋药用生物资源可持续利用潜力 影响很大。海洋生物医药产业作为高新技术产业, 政策支持能为产业的发展提供良好的社会环境,也 能在一定程度上促进海洋生物医药产业的发展, 同 时有效的法律法规能为海洋药用生物资源可持续 利用提供制度保障。海洋药品市场辐射能力表示 海洋药品市场前景, 辐射能力越强说明海洋药品市 场越广阔, 需求比较旺盛, 成熟的市场会形成有效 的机制, 对海洋药用生物资源可持续利用形成一个 良性循环。海洋药用生物资源的生长和繁衍依赖 于环境的多样性。环境的完整性会对海洋药用生 物资源的种类和数量产生很大影响, 环境多样性是 海洋药用生物资源可持续利用的环境基础。药用 生物资源供给数量是海洋生物医药产业发展的资 源基础, 在产业发展到一定规模时,产业发展规模 会在一定程度上影响药用资源开发规模,对海洋药 用生物资源可持续利用产生影响。药用资源研发
水平会影响海洋生物医药产业的产品更新速度和 产品结构,进而会影响海洋生物医药产业的发展; 同时,海洋生物医药产业的发展又会对海洋药用生 物资源可持续利用产生影响。

(2)评价指标中海洋药业增加岗位数量、海洋药 品市场化水平、全国人均收人增长、人均药用资源 量和药用资源占海洋生物比重的权重居于后 5 位。 说明这 5 项指标对海洋药用生物资源可持续利用潜 力影响较小。海洋生物医药产业发展可增加海洋 药业岗位数量; 反过来增加海洋药用生物岗位能在 一定程度上促进海洋生物医药产业规模提高, 是间 接影响海洋药用生物资源可持续利用潜力。海洋 药品的功能决定海洋药品市场化, 为此需要增强海 洋药品的功能性和不可替代性能促进海洋药品市 场化。全国人均收人增长水平代表了人的消费能 力。人均药用资源量表示人均占有海洋药用生物 资源。由于中国人口众多, 人均占有海洋药用生物 资源只能在一定程度上反映海洋药用生物资源特 性,对海洋药用生物资源可持续利用影响较小。

\section{4 数据来源及处理方法}

根据评价指标体系中的各指标特点, 结合数据 的可得性和准确性, 本文的数据来源主要有以下四 个方面：

(1)实践调研。通过参与国家科技基础性工作 专项项目 “中国近海重要药用生物和药用矿物资源 调查”研究、参与广西海洋专项“海洋生物资源开发 利用潜力研究”、主持国家海洋局软科学项目“青岛 区域海洋生物资源资产化管理”等项目研究,获取 评价指标体系中的 $D_{2} 、 D_{5} 、 D_{6} 、 D_{7} 、 D_{8}$ 指标数据。

(2)专家调查问卷。通过在“中国第十二届海 洋药物学术年会”发放专家调查问卷,针对不同沿 海省市调查指标数据。共发放 150 份, 收回 131 份, 获取评价指标体系中的 $D_{1} 、 D_{3} 、 D_{4} 、 D_{9} 、 D_{10} 、 D_{11} 、 D_{15}$ 、 $D_{19}$ 指标数据。

(3)社会调查问卷。首先通过在“中国第十二 届海洋药物学术年会” 发放调查问卷 (同上), 获取 相关调查指标数据。然后又通过 11 个沿海省市海 洋相关高校学生在相关省市发放社会调查问卷,每 省市发放 100 份,共发放 1100 份, 回收 852 份。综合 这两个数据来源获取评价指标体系中的 $D_{12} 、 D_{13}$ 、 
$D_{14} 、 D_{16} 、 D_{17}$ 指标数据。

(4)公开数据统计资料。通过中国海洋统计年 鉴、国家经济统计公报等官方资料,获取评价指标 体系中的 $D_{18} 、 D_{20}$ 指标数据。

评价指标体系中的指标数据分为定量和定性 两种。对于定性数据, 除去误差较大数据, 求取算 数平均值, 得到指标数据; 对于定量数据, 比较不同 统计年鉴统计口径, 选取权威性较强的统计数据, 将原始数据进行无量纲化处理, 之后得到指标 数据。

\section{3 结果及分析}

\section{1 沿海 11 省海洋药用生物资源利用潜力结果}

根据上述指标体系制作调查问卷,结合专家打 分法, 选取 36 位专家问卷对沿海 11 省市各项指标 打分的平均值为指标得分 (各项指标最高分 10 分, 最低分 0 分), 并分别乘以各项指标对应的最终权 重, 可得全国沿海 11省市指标分数总分。经处理后 可得大陆沿海 11 省市海洋药用生物资源可持续利 用潜力总分,并根据总分大小排序, 见表 6 。
由表 6 可知, 中国沿海 11省市海洋药用生物资 源可持续利用潜力总分排序依次为广东、浙江、海 南、山东、福建、江苏、广西、上海、天津、辽宁以及 河北。

由沿海 11 省市得分划分为 3 个区间,综合得分 区间分别为 $(7.5,8.5] 、(6.5,7.5] 、[6.5$ 以下], 不同区 间为不同等级。在第 1 等级中最终权重排名前 5 的 主要指标得分和综合得分均位于前列, 发展海洋生 物医药产业潜力最大。第 2 等级综合得分较高, 尽 管 5 项主要指标得分之间有差异,发展海洋生物医 药产业潜力较大。第 3 等级 5 项主要指标得分和综 合得分均较低, 发展海洋生物医药产业潜力较低。 所以中国沿海 11省市海洋药用生物可持续开发利 用潜力又可分为 3 个等级, 见表 7 。

\section{2 沿海 11 省市海洋药用生物资源可持续开发利 用潜力分析}

由表 7 可知,第 1 级有广东、浙江; 第 2 级有海 南、山东、福建、江苏、广西、上海;第 3 级有天津、辽 宁、河北。

\section{表 6 中国沿海 11 省市海洋药用生物资源利用潜力}

Table 6 The sustainable development potential of marine medicinal bioresources in 11 coastal provinces and municipalities in China

\begin{tabular}{|c|c|c|c|c|c|c|c|c|c|c|c|}
\hline 省份评价指标 & 广东 & 浙江 & 海南 & 山东 & 福建 & 江苏 & 广西 & 上海 & 天津 & 辽宁 & 河北 \\
\hline 环境多样性 $D_{1}$ & 0.6076 & 0.5452 & 0.6566 & 0.5100 & 0.5436 & 0.4861 & 0.5945 & 0.4280 & 0.3635 & 0.3459 & 0.3283 \\
\hline 可药用资源种类 $D_{2}$ & 0.5285 & 0.4598 & 0.5488 & 0.4054 & 0.4962 & 0.4315 & 0.4554 & 0.3461 & 0.3065 & 0.3213 & 0.2867 \\
\hline 可药用资源总量 $D_{3}$ & 0.4517 & 0.3972 & 0.4605 & 0.3676 & 0.4287 & 0.3641 & 0.3280 & 0.2958 & 0.2746 & 0.2746 & 0.2493 \\
\hline 人均药用资源量 $D_{4}$ & 0.2059 & 0.1838 & 0.2083 & 0.1471 & 0.1667 & 0.1544 & 0.0474 & 0.1397 & 0.1348 & 0.0980 & 0.1226 \\
\hline 药用资源占海洋生物比重 $D_{5}$ & 0.1810 & 0.1672 & 0.1947 & 0.1718 & 0.1879 & 0.1627 & 0.0227 & 0.1581 & 0.1375 & 0.1145 & 0.1260 \\
\hline 可养殖药用资源种类 $D_{6}$ & 0.2971 & 0.2752 & 0.2552 & 0.2666 & 0.2846 & 0.2627 & 0.1560 & 0.1978 & 0.1663 & 0.2122 & 0.1835 \\
\hline 可养殖药用资源数量 $D_{7}$ & 0.3570 & 0.3340 & 0.3104 & 0.2969 & 0.3349 & 0.3018 & 0.1612 & 0.2294 & 0.1990 & 0.2294 & 0.1923 \\
\hline 药用资源供给种类 $D_{8}$ & 0.3903 & & 0.3372 & 0.3364 & 0.3140 & 0.3095 & 0.1738 & 0.2826 & 0.2422 & 0.2512 & 0.2422 \\
\hline 药用资源供给数量 $D_{9}$ & 0.4764 & 0.4319 & 0.5018 & 0.4764 & 0.4383 & 0.4256 & 0.5413 & 0.3621 & 0.3367 & 0.3049 & 0.2985 \\
\hline 药用资源研发水平 $D_{10}$ & 0.3085 & 0.2704 & 0.2227 & 0.2767 & 0.2576 & 0.2354 & 0.1309 & 0.2608 & 0.1908 & 0.1908 & 0.1686 \\
\hline 海洋药品市场化水平 $D_{11}$ & 0.2425 & 0.2174 & 0.1700 & 0.2174 & 0.1979 & 0.2090 & 0.0417 & 0.2035 & 0.1589 & 0.1644 & 0.1477 \\
\hline 海洋药品市场知名度 $D_{12}$ & 0.3031 & 0.2492 & 0.2055 & 0.2897 & 0.2290 & 0.2459 & 0.0968 & 0.2290 & 0.1819 & 0.1920 & 0.1684 \\
\hline 海洋药品市场辐射能力 $D_{13}$ & 0.6448 & 0.6309 & 0.5408 & 0.6101 & 0.5685 & 0.5685 & 0.6203 & 0.6101 & 0.4546 & 0.4784 & 0.4784 \\
\hline 海洋药品市场饱和度 $D_{14}$ & 0.4109 & 0.3522 & 0.3025 & 0.3703 & 0.3432 & 0.3296 & 0.3167 & 0.3251 & 0.2754 & 0.2619 & 0.2303 \\
\hline 政策支持强度 $D_{15}$ & 1.6057 & 1.4746 & 1.2944 & 1.4746 & 1.3763 & 1.3108 & 2.0447 & 1.3600 & 1.0323 & 1.0323 & 0.9012 \\
\hline 公众了解程度 $D_{16}$ & 0.3066 & 0.2962 & 0.2718 & 0.2962 & 0.2683 & 0.2718 & 0.3070 & 0.2857 & 0.2509 & 0.2439 & 0.2091 \\
\hline 公众认可程度 $D_{17}$ & 0.3443 & 0.3310 & 0.3310 & 0.3001 & 0.2957 & 0.3222 & 0.3075 & 0.3045 & 0.2163 & 0.2516 & 0.2348 \\
\hline 海洋药业增加岗位数量 $D_{18}$ & 0.2401 & 0.2369 & 0.2209 & 0.2081 & 0.2081 & 0.2177 & 0.2091 & 0.2209 & 0.1793 & 0.1697 & 0.1441 \\
\hline 海洋药业增加岗位水平 $D_{19}$ & 0.2642 & 0.2384 & 0.2223 & 0.2449 & 0.2159 & 0.2159 & 0.2091 & 0.2481 & 0.1708 & 0.2094 & 0.1482 \\
\hline 全国人均收人增长 $D_{20}$ & 0.2254 & 0.2427 & 0.2340 & 0.2196 & 0.2196 & 0.1994 & 0.1480 & 0.2571 & 0.2080 & 0.1531 & 0.1762 \\
\hline 总分 & 8.3915 & 7.6708 & 7.4894 & 7.4859 & 7.3749 & 7.0244 & 6.9121 & 6.7443 & 5.4802 & 5.4996 & 5.0364 \\
\hline
\end{tabular}


表 7 中国沿海 11 省市海洋药用生物资源可持续开发利用潜力等级分布

Table 7 The grades of marine medicinal bioresources sustainable development potential in 11 coastal provinces and municipalities in China

\begin{tabular}{llll}
\hline 海洋药用生物可持续开发利用潜力等级 & 第 1级得分区间为[7.5 8.5] & 第2级得分区间为 $[6.5 \sim 7.5]$ & 第3级得分区间为 [6.5 以下] \\
\hline 省市 & 广东、浙江 & 海南、山东、福建、江苏、广西、上海 & 天津、辽宁、河北 \\
\hline
\end{tabular}

\subsection{1 第 1 等级:广东和浙江两省}

两省综合指标和分项指标得分都很高, 说明两 省海洋药用生物资源可持续利用潜力总分最高。 其中政策支持强度贡献率最大, 其次为海洋药品市 场辐射能力、环境多样性以及可药用资源种类的贡 献率。这可以说明海洋药用生物资源可持续开发 利用在一定程度上是政策导向型。广东位于珠江 三角洲地区, 为海洋经济试点省区, 具有良好的经 济基础和政策基础。浙江是中国经济最活跃的省 份之一,国有经济与民营经济相互促进,形成了具 有鲜明特色的“浙江经济”现象。首个以海洋经济 为主题的国家级新区就坐落于浙江。两省都应该 充分利用其政策优势,保护性开发利用海洋药用生 物资源, 提高海洋药用生物资源可持续利用潜力, 进一步促进海洋生物医药产业发展。

3.2.2 第 2 等级有海南、山东、福建、江苏、广西和上 海六省市

根据得分结果, 具体潜力状况如下:

(1)海南和广西的环境多样性、可药用资源种 类和数量都居前列, 这说明这两省有坚实的医药产 业发展物质基础。其中海南政策支持强度、海洋药 品市场辐射能力在第 2 等级得分最低; 广西海洋药 用生物研发水平、海洋药品市场化水平、海洋药品 市场知名度得分均远低于其他沿海省市。这使得 两省海洋药用生物资源可持续利用潜力等级不高, 综合得分偏低。

(2) 山东和福建在第 2 等级中综合得分处于前 列，其政策支持强度、药用资源研发水平和可养殖 药用资源种类在第 2 等级中尤其突出, 这说明两省 具有良好的政策环境、科研研发技术和坚实的资源 基础。

(3)江苏和上海在第 2 等级中综合得分处于中 等偏下水平。其中上海的政策支持强度、海洋药品 市场辐射能力、药用资源研发水平得分在第 2 等级 中最高,其中药用资源研发水平得分在中国沿海 11
个省市中居于前列。上海具有良好的科研研发环 境,而且科研水平在全国具有影响力。

3.2.3 第 3 等级: 天津、辽宁和河北三省市

三省市各项指标及综合得分都很低,海洋药用 生物资源开发利用潜力较差。其中河北省海洋药 用资源总量最低, 缺少发展海洋生物医药产业的物 质基础。

\section{4 沿海 11 省市海洋药用生物资源开发 利用发展对策}

结合海洋药用生物资源潜力评价实证结果, 提 出如下保护性开发利用海洋药用生物资源建议:

\section{1 总体发展对策}

4.1.1 政策举措方面一一明确发展目标,强化政策 引导

适宜发展海洋生物医药产业的省市应明确海 洋药用生物发展的重点目标, 充分利用现有产业基 础和自然资源优势,做好产业布局。由政府主导， 建立“政府-产业-学校-科研院所-商业-金融”为一体 的合作平台，从财政、税收以及奖励机制等方面鼓 励各方积极加人合作平台。

4.1.2 资源环境方面一一加强资源环境保护, 实现 可持续利用

海洋药用生物资源是海洋生物医药产业发展 的物质基础。只有资源、环境与社会经济协调发 展,才能充分发挥三者的协同作用,促进经济可持 续发展。为此,需要建立政府各部门之间协调合作 机制, 充分考虑资源环境的承载力, 控制近海环境 污染,建立完善海洋药用生物资源自然保护区,实 现保护性开发利用。

4.1.3 企业发展方面一以产业园为载体, 构建合 作平台体系

借鉴国内外产业聚集园区的发展模式,逐渐形 成强有力的品牌和沟通战略,提升产业园区的形象 和知名度; 依靠生态型资源循环, 建立分工合作机 制,完善产业链条,实现低碳经济和循环发展,形成 
规模与效益并进的格局。

4.1.4 科研技术方面一一加强人才培养与引进, 加 快技术创新与成果转化

科技是产业发展的主要驱动力, 建议以国家投 人为主，同时倡导多元化、社会化的科研投人机制， 推进技术创新,加速科研成果的产业化转化。政府 应当设立研发推广资金, 以课题申报的形式,重视 国内专业人才培养, 系统地吸引国内外海洋药用生 物技术研究的顶尖人才,有目的地组织海洋药用生 物技术的研究开发及推广。

\section{2 分级发展建议}

\subsection{1 第 1 等级}

大力发展海洋医药产业, 发挥带头作用, 提升 全国海洋生物医药产业发展水平。广东和浙江两 省具有丰富的海洋药用生物资源、强力的政府支持 力度以及先进的科研水平,应该发挥其产业集聚效 应和规模效应, 打造海洋生物医药产业特色品牌, 扩大市场辐射范围, 促进海洋生物医药产业规模 发展。

\subsection{2 第 2 等级}

山东与福建有青岛和厦门为中心的海洋药用 生物及海洋生物技术研究中心, 不仅有丰富的海洋 药用生物资源, 还具有相关科研优势, 对于发展海 洋生物医药产业具有得天独厚的条件。但是山东 和福建的科研成果转化率较低, 市场辐射能力较 弱, 还需加强政策的引导,加快科研成果的转化, 促 进两省制药产业的顺利转型。同时需要注意保护 海洋生态环境, 实现海洋药用生物资源可持续开发 利用。上海经济和金融实力雄厚,政策支持和研发 优势显著,应该加快研发步伐,提高科研成果转化 率; 打造优势品牌, 并且利用其较强的市场辐射能 力开拓市场, 带动整体产业发展。江苏经济综合实 力一直处于我国前列, 进一步加强政策支持力度, 发挥资源优势、借力山东和上海的研发技术形成本 土化品牌, 进一步扩大市场辐射范围, 促进海洋生 物医药产业发展。

海南和广西具有丰富的海洋药用生物资源, 具 有独特的海洋药用生物资源优势, 具备发展海洋生 物医药产业的物质条件。但其科研水平较弱、市场 开发程度较低和海洋药用生物资源环境被破坏等
因素制约了海洋生物医药产业的发展。因此,这两 个省份应该加大海洋药用生物资源环境保护力度, 完善相关法律法规; 以本地化海洋药用生物资源为 基础,加强与科研具有优势的省份合作和政府科研 投人的力度, 促进海洋生物医药产业发展。广西还 应该利用特色资源优势, 借助东盟自贸区平台, 发 挥桥头堡作用, 积极与周边国家进行合作, 实现海 洋生物医药产业国际化发展。

\subsection{3 第 3 等级}

天津、辽宁和河北可以根据当地政策优势,结 合周边区域的技术外溢效应,加大投资力度, 建立 战略联盟,借助其他省份的资源和技术优势形成特 色发展模式促进海洋生物医药产业发展。

\section{5 结论与讨论}

\section{1 结论}

（1）本文针对海洋药用生物资源特点, 构建了 海洋药用生物资源可持续利用潜力评价指标体系, 从目标层、制约层和要素层 3 个层次选取富有代表 性的 20 项指标, 全面客观地反映了海洋药用生物资 源潜力情况。并采用 1-9 标度法对评价指标进行标 准量化, 以及用层次分析法和熵权法为各指标赋予 其相应的权重。通过权重分析可知: 制约层中,社 会条件在海洋药用生物资源潜力评价中所占权重 最大。在要素层中,药用资源丰度在自然条件子系 统中所占权重最大,技术成熟度在经济与技术条件 子系统中所占权重最大,政府支持力度在社会条件 子系统中所占权重最大。由此可见,海洋药用生物 资源开发必须有重点、有层次地推进, 海洋药用生 物资源可持续利用潜力是以药用资源丰度为基础, 以技术成熟度为条件, 以政府支持为保障, 与社会 发展阶段相关联。

(2)本文依据构建海洋药用生物资源可持续利 用潜力评价模型, 对中国沿海 11 个省市进行实证分 析, 并设定了评价等级标准,其中第 1 等级为广东、 浙江; 第 2 等级为海南、山东、福建、江苏、广西、上 海; 第 3 等级为天津、辽宁、河北, 为海洋药用生物资 源可持续利用潜力评价与分级提供了科学依据。 综合指标贡献度的实证结果表明,中国海洋药用生 物资源可持续利用潜力具有差异性,其主要影响因 素为政府支持强度、海洋药品市场辐射能力、环境 
多样性、药用资源供给数量和药用资源研发水平。 第 1 等级的两省应大力发展海洋生物医药产业,第 2 等级和第 3 等级的省市应凭借其独特优势, 弥补 不足,积极发展海洋生物医药产业。此评价方法能 比较客观地评价沿海 11 个省市的海洋药用生物资 源可持续发展潜力, 对海洋药用生物资源可持续开 发利用具有指导意义。

\section{2 讨论}

（1）由于海洋药用生物资源具有区域差异化特 征, 本文从总体和分级两方面提出对策建议。总体 方面,从政府政策、资源环境、企业方面以及科研投 人方面提出了提高海洋药用生物资源潜力方面的 相关建议。分级方面,则依据不同省市要素禀赋, 针对具体省市现状与问题,提出不同的建议措施, 以期实现海洋生物医药产业健康持续发展。

(2)本文以理论研究为重点,构建了海洋药用 生物资源可持续利用潜力评价体系, 在实际应用中 应注意以下两点: 首先, 权重设定以专家打分为样 本,结果带有一定的主观性,在计算过程中应根据 相应地区发展现状进行必要的检验与修正; 其次, 各地区海洋药用生物资源禀赋与开发重点相异,在 具体指标与权重设定上, 可以在本文的研究框架 内,根据实际情况对细节进行适当的处理和调整。 本文所构建的海洋药用生物资源可持续利用潜力 评价直观简便, 具有较强的实用性。由于海洋药用 生物资源系统复杂多样,采用更全面的定性方法选 取评价因子,采用更科学的定量方法制定权重,可 以使研究更为完善和系统。

\section{参考文献(References) :}

[1] 前瞻产业研究院. 2013-2017年中国海洋生物医药产业深度调 研与投资战略规划分析报告 $[\mathrm{M}]$. 北京: 前沿产业研究院, 2013. [Foresight Industry Research Institute. Report of depth Research and Investment Strategy Planning on China Marine Biological Medicine Manufacturing Industry (2013-2017) [M] Beijing: Foresight Industry Research Institute, 2013.]

[2] 傅秀梅, 王长云, 邵长伦, 等. 中国海洋药用生物濒危珍稀物种 及其保护 $[J]$. 中国海洋大学学报 (自然科学版), 2009, 39(4): 719-728. [Fu X M, Wang C Y, Shao C L, et al. Chinese Marine medicinal and endangered rare species and their protection[J].
Periodical of Ocean University of China, 2009, 39(4): 719-728.]

[3] 张宏亮. 自然资源估价理论与方法研究-基于宏观环境会计的 视角 [J]. 山西财经大学学报, 2007, 29(3): 15-20. [Zhang H L. Natural resources evaluation theories and method analysis-from the perspective of macro- environmental accounting[J]. Journal of Shanxi Finance and Economics University, 2007, 29(3) : 1520.]

[4] 刘德团, 李婉莎, 和玉龙, 等. 玉龙雪山种子植物资源评价 [J]. 植物分类与资源学报, 2015, 37(3): 318-326. [Liu D T, Li W S, He Y L, et al. Resources evaluation of seed plants in Yulong Snow Mountain, Lijiang, Northwestern Yunnan[J]. Plant Diversity and Resources, 2015, 37(3):318-326.]

[5]杨庆安, 陆明金金, 陆奇勇, 等. 湘西南龙底保护区药用种子植物 功效组成特征及资源评价 [J]. 现代农业科技, 2012, 33(1)： 150-152. [Yang Q A, Lu M X, Lu Q Y, et al. Effect composition characteristics and resource assessment of medicinal seed plants in Longdi Nature Reserve in Southwestern Hunan[J]. Modern Agricultural Science and Technology, 2012,33(1): 150-152.]

[6] 周亚福, 李思锋, 黎斌, 等. 基于层次分析法的秦岭重要药用植 物资源评价研究 [J]. 中草药, 2013, 44 (15): 2172-2182. [Zhou Y F, Li S F, Li B, et al. Evaluation of important medicinal plant resources in Qinling Mountains based on analytic hierarchy process method[J]. Chinese Traditional and Herbal Drugs, 2013, 44(15):2172-2182.]

[7] 尚迪, 刘玉珊, 白为, 等. 川西北六种濒危药用植物资源开发利 用价值评价[J]. 南方农业, 2015,9(19):31-34. [Shang D, Liu Y $\mathrm{S}$, Bai $\mathrm{W}$, et al. Evaluation of the utilization value of six endangered medicinal plant resources in Northwest Sichuan[J]. South China Agriculture, 2015, 9(19):31-34.]

[8] 宁小清, 林荣波, 谈远锋, 等. 广西药用红树植物种类及其民间 药用功效研究 [J]. 中国医药指南, 2013, 11 (18): 73-75. [Ning X Q, Lin Y B, Tan Y F, et al. The kinds of plants and their folk medicinal properties of guangxi medicinal plants[J]. Guide of China Medicine, 2013,11(18): 73-75.]

[9] 王金辉,孙亚伟, 秦玉涛, 等. 嵊山岛海洋药用生物资源状况调 查 [J]. 氨基酸和生物资源, 2006, 28(1): 1-5. [Zhang J H, Sun Y $\mathrm{W}$, Qin Y T, et al. The preliminary investigation of marine drug resources in Shenshan Island[J]. Amino Acids and Biotic Resources, 2006,28(1): 1-5.]

[10] 张梦启, 白虹, 王毓, 等.中国海洋中药材品种调查 [J]. 中国海 洋药用生物, 2014, 33 (6): 39-46. [Zhang M Q, Bai H, Wang L, et al. Investigation on the varieties of marine traditional Chinese medicines in China[J]. Chinese Journal of Marine Drugs, 2014, 33(6):39-46.]

[11] 吕永龙, 苑晶晶, 李奇锋, 等. 陆源人类活动对近海生态系统的 影响[J]. 生态学报, 2016, 36(5): 1183-1191. [Lu Y L, Yuan J J, Li Q F, et al. Impacts of land-based human activities on coastal 
and offshore marine ecosystems[J]. Acta Ecologica Sinica, 2016 36(5): 1183-1191.]

[12] 王如松, 欧阳志云. 社会-经济-自然复合生态系统与可持续发 展 [J]. 中国科学院刊, 2012, 27 (3) : 337-345. [Wang R S, Ouyang Z Y. Social-economic-natural complex ecosystem and sustainability[J]. Chinese Academy of Sciences, 2012, 27 (3):
337-345.]

[13] 王泽宇, 卢函孙, 孙才志, 等. 中国海洋经济系统稳定性评价与 空间分异 [J]. 资源科学, 2017, 39(3): 566-576. [Wang Z Y, Lu $\mathrm{H}$, Sun C Z, et al. Assessment and spatial differentiation of China's marine economic system stability[J]. Resources Science, 2017,39(3): 566-576.]

\title{
Evaluation on the sustainable utilization potential of marine medicinal bioresources in China based on Entropy-AHP
}

\author{
DAI Guilin ${ }^{1}$, LIN Chunyu ${ }^{1}$, FU Xiumei ${ }^{1}$, WANG Na ${ }^{1}$, LI Yusen ${ }^{1}$ \\ (College of Economics, Ocean University of China, Qingdao 266100, China)
}

\begin{abstract}
Resource is the material basis for industrial development. This study focuses on quantitative calculation and rank for marine medicinal bioresources in sustainable utilization potential in coastal provincial-level areas of China (excluding Hong Kong, Macao and Taiwan), and then evaluates the development potential of regional marine biopharmaceutical industry, aiming to provide references for decision making on optimizing the allocation of resources and layouts industries reasonably. We select 20 impact factors from three aspects: natural conditions, economic and technological conditions, and social conditions. Then, we calculate weight values of 20 factors obtained through Analytic Hierarchy Process (AHP) and Entropy method, and further establish a system for evaluating sustainable utilization potential of marine medicinal bioresources. It is found that the top five weight values of 20 factors are policy support strength, marine biopharmaceutical market radiation, environmental diversity, the amount of supply of marine medicinal bio- resources, and the level of research and development of medicinal bioresources, which are the main factors influencing sustainable utilization potential of marine medicinal bioresources. The above evaluation system is applied to 11 provincial-level areas in coastal, China. Results show that Guangdong and Zhejiang are in the first grade. Hainan, Shandong, Fujian, Jiangsu, Guangxi, and Shanghai are in the second grade. Liaoning, Hebei and Tianjin are in the third grade. Finally, considering the contribution degree of the main influencing factors, we propose suggestions for these provincial- level areas which can promote the development marine biopharmaceutical industries, and enhance sustainable utilization potential of marine medicinal bio-resources.
\end{abstract}

Key words: marine medicinal bioresource; sustainable utilization; potential evaluation; entropy; AHP 